\title{
Experimental Exploration of Bearing Capacity of Clay with Multiple Inflatable Anchors
}

\author{
Qiu-nan Chen, ${ }^{1}$ Meng Yang, ${ }^{1}$ and Xiao-cheng Huang $\mathbb{D}^{1,2}$ \\ ${ }^{1}$ School of Civil Engineering, Hunan Univ. of Science and Technology, Xiangtan 411201, China \\ ${ }^{2}$ National Engineering Laboratory of Highway Maintenance Technology, Changsha University of Science \& Technology, Changsha, \\ 410114 Hunan, China
}

Correspondence should be addressed to Xiao-cheng Huang; xchuang@cqu.edu.cn

Received 25 July 2020; Revised 14 November 2020; Accepted 26 November 2020; Published 14 December 2020

Academic Editor: Hang Lin

Copyright (c) 2020 Qiu-nan Chen et al. This is an open access article distributed under the Creative Commons Attribution License, which permits unrestricted use, distribution, and reproduction in any medium, provided the original work is properly cited.

Inflatable anchors have been applied to reinforce foundations because soft soil deposits have a low bearing capacity. However, previous research on the mechanical behaviors of inflatable anchors has focused on a single anchor. Since anchors are always used in a group, the uplift behavior of multiple inflatable anchors in soft soil should be investigated. A series of pull-out tests were conducted in this framework by changing the number, spacing, and layout of inflatable anchors. Additionally, the effect coefficient (ECO) of multiple inflatable anchors is discussed. It is found that the failure behavior of multiple inflatable anchors exhibits a three-stage curve: an initial linear stage, followed by nonlinear, and steady-state stages. In addition, the ultimate bearing capacity of multiple inflatable anchors is maximized if the ratio of the spacing of inflatable anchors to the equivalent expanding section diameter of an inflatable anchor is 6.84. It is recognized that the ECO of this new multiple inflatable anchor group is sometimes greater than 1, unlike that of conventional anchors, which have ECOs of less than 1 . In addition, the layout of multiple inflatable anchors in the shape of a cinquefoil is recommended due to its high ECO.

\section{Introduction}

Soft soils are commonly found in coastal regions. Currently, infrastructure and other structures are constructed over soft soils because there is an increasing lack of suitable land. However, the bearing capacity of soft soil deposits is not sufficient, thereby challenging geotechnical engineers during the design stage of their work. One of the techniques used to overcome the insufficient bearing capacity of soft soil is the application of pile/anchor-reinforced foundations [1-4].

Due to their safety and convenience, anchors are utilized for supporting a sufficient force for structures (such as tunnels, deep excavations, and slopes). Inspired by this approach, a new anchor with an enhanced bearing capacity was invented by Newson et al. [5]. This new anchor consists of a valve at the top of an inflatable anchor, a rod as the body, and rubber(s) membrane at the bottom. As the rubber membrane is charged with gas or air, this type of anchor is called an inflatable anchor. The main characteristic of inflatable anchors is that the bearing capacity can be enhanced by the charged rubber. The behaviors of inflatable anchors were simulated using a nonlinear finite element method by Peng et al. $[6,7]$. It was found that the limit displacement is linear to the inflation pressure of the rubber, and the relationship between the anchoring force and rubber membrane length is also linear. Mo [8] invented a bladder-type inflatable anchor that is similar to a group blade helical anchor, and its bearing capacity was studied by laboratory model testing. Compared with an ordinary inflatable anchor, the ultimate uplift bearing capacity of the bladder-type inflatable anchor is better. In a theoretical approach, the expansion of rubber is treated as the expansion of a circular cavity, and its mechanism was investigated by Cao and Peng [9] and Cao et al. [10] according to a modified Cambridge model. The results determined from theoretical formulas are compared with those obtained by experiments. The estimation formula of the ultimate bearing capacity to inflatable anchors, considering branches attached to soil, was proposed by Yang et al. [11]. A new type of recycle material was applied to the inflatable anchor, so that the anchors were recyclable [12]. Yang 


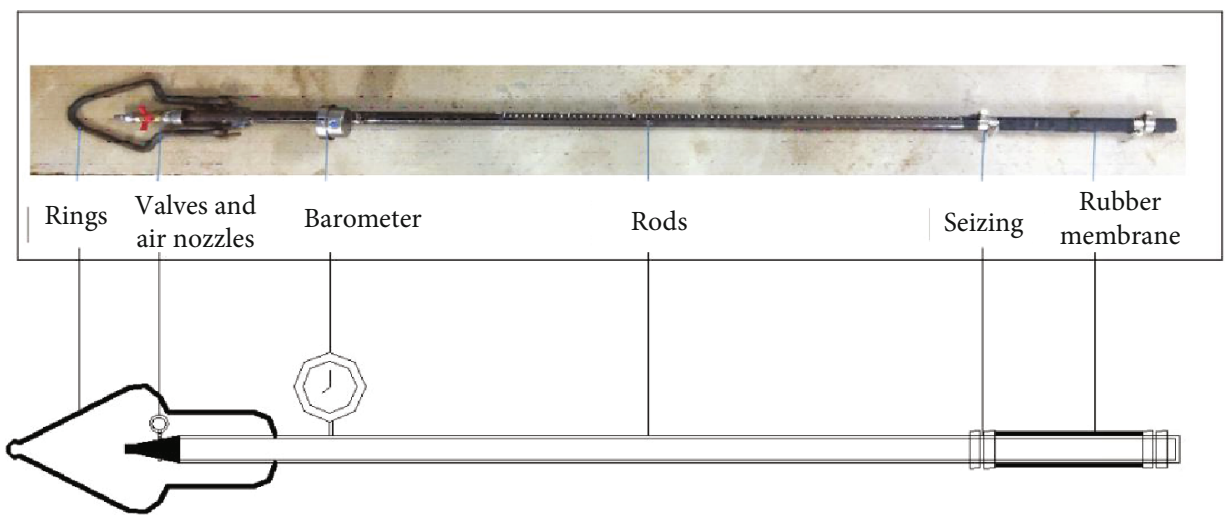

Figure 1: Physical model of inflatable anchor and its structure.

et al. [13] developed aerated expansion controlled anchors, where the maximum ultimate bearing capacity $(40 \mathrm{kN})$ of the anchor section per meter was enhanced to 60 times that of the existing aerated anchor. However, a major concern of scholars is that the design and analysis of these inflatable anchors is based on a single anchor. The stabilization system may fail if there is no sufficient uplift capacity on a single anchor. Additionally, multiple inflatable anchors are used in engineering projects. In view of this, the uplift mechanism of multiple inflatable anchors needs to be better understood. However, very few studies investigating this issue have been reported.

In this study, the mechanical behaviors of multiple inflatable anchors in clay were investigated. The testing groups were divided according to different numbers, spacing, and layouts of the inflatable anchors. A series of pull-out loaddisplacement relationships of inflatable anchors were obtained, and the results were carefully analyzed. The ECO of group anchors is also discussed as it can indicate important characteristics of the group anchors.

\section{Model Test Equipment}

2.1. Design of the Inflatable Anchor. As shown in Figure 1, the inflatable anchor model is mainly made of rubber membrane, rods, and valves. For an inflatable anchor, the length of the rods, hoisting ring, and total length are $1.8 \mathrm{~m}, 0.2 \mathrm{~m}$, and $2 \mathrm{~m}$, respectively. The rubber membrane can be charged with air or another gas, and its length and thickness can be changed as required. The rod is a seamless steel tube with a scale to enable reading the displacement. The process for charging the gas can be controlled by valves at the top of anchor. In addition, other accessories such as air nozzles, a seizing, and rings are also depicted in Figure 1. It should be noted that the ring is used for load application and can be upscaled in engineering projects.

2.2. Design of the Model Test. The total size of the test tank is $2000 \mathrm{~mm} \times 2000 \mathrm{~mm} \times 1000 \mathrm{~mm}$ (Figure 2(a)). The loading device is designed as shown in Figure 2(b). The model test is composed of an antiforce device, test tank, loading system, and data acquisition system. The test tank is a brick concrete wall, approximately $240 \mathrm{~mm}$ thick. PVC drainage pipes are laid at the bottom of the test tank.

The testing procedure is described as follows:

(1) First, the inflatable anchors should be empty and fixed to the support frame. The guide pipes should be horizontal

(2) Clay is added into the test tank, and the anchors are kept vertical. The parameters of the clay are presented in Table 1. Each anchor is equipped with a water level, which is used to determine whether the anchor is inclined

(3) The data acquisition system is installed

(4) The rubber membrane is charged to the designed value

(5) The inflatable anchors are loaded by lifting the jack, and the results are read by the data acquisition system

Before the inflatable anchor tests are conducted, the geoparameters of the testing soil should be investigated. The testing soil was drilled near Xiangjiang River, as shown in Figure 3, which is located in Xiangtan, China. A series of experimental methods were conducted to study the properties of the soil, such as the specific gravity bottle method (Figure 4(a)), direct shear test method (Figure 4(b)), compaction test (Figure 4(c)), and liquid-plastic combine test (Figure 4(d)). In Figure 5, the moisture content versus dry density of the soil is plotted. The testing results are listed in Table 1.

From Table $1, I_{p}$ is the plasticity index and $\omega_{L}$ is the liquid limit of the soil. It is indicated that the plasticity index is greater than 17 and that the liquid limit index is less than 50\%. From the testing results of the soil, it is determined to be clay.

\section{Experimental Program}

3.1. Single Inflatable Anchor Test. Before investigating the uplift bearing capacity of multiple inflatable anchors, the uplift behaviors of a single inflatable anchor should be studied first. The testing procedures were described above, and the results are listed in Table 2 . The embedment depth of 


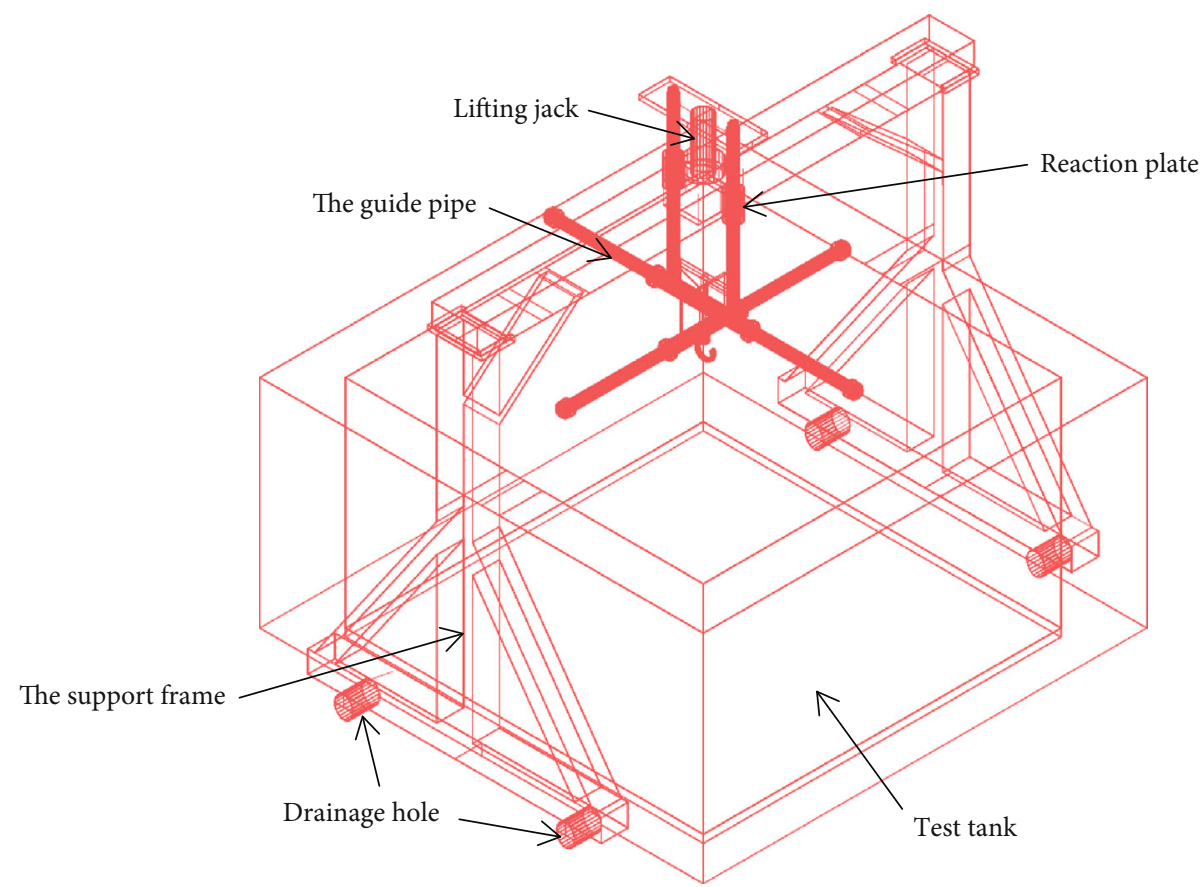

(a) Diagram of the model test

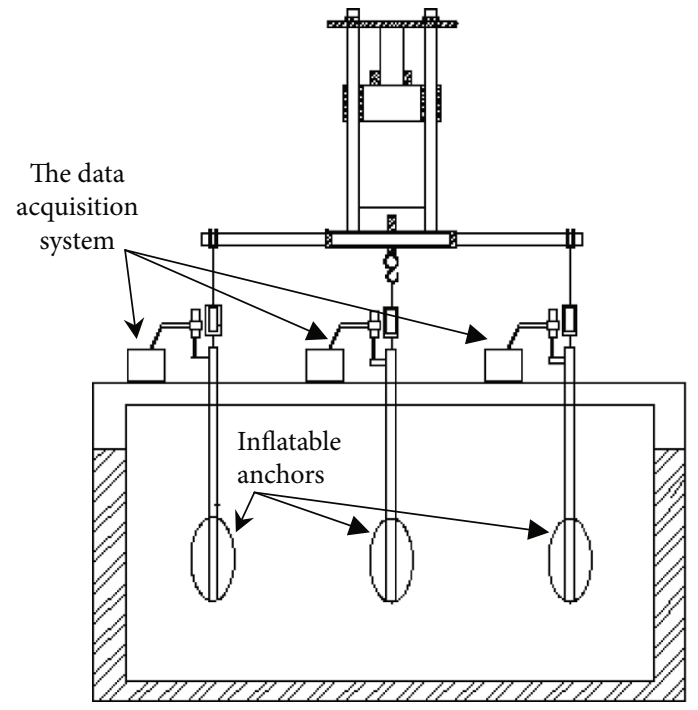

(b) Loading device

FIgURE 2: Schematic diagram of the model test.

TABLE 1: The geoparameters of the testing soil.

\begin{tabular}{lcccccccc}
\hline $\begin{array}{l}\text { Specific } \\
\text { gravity }\end{array}$ & $\begin{array}{c}\text { Plastic limit } \\
(\%)\end{array}$ & $I_{p}$ & $\begin{array}{c}\omega_{L} \\
(\%)\end{array}$ & $\begin{array}{c}\text { Water content } \\
(\%)\end{array}$ & $\begin{array}{c}\text { Degree of compaction } \\
(\%)\end{array}$ & $\begin{array}{c}\text { Maximum dry density } \\
\left(\mathrm{g} / \mathrm{cm}^{3}\right)\end{array}$ & $\begin{array}{c}\text { Cohesion } \\
(\mathrm{kPa})\end{array}$ & $\begin{array}{c}\text { Friction angle } \\
\left({ }^{\circ}\right)\end{array}$ \\
\hline 2.692 & 15.90 & 17.7 & 33.64 & 28 & 83 & 1.88 & 17.6 & 23.1 \\
\hline
\end{tabular}

the anchors was $45 \mathrm{~cm}$, and the rubber membrane was charged with air. The testing for a single inflatable anchor includes two groups, and the average ultimate uplift bearing capacity $\left(U_{b}\right)$ and average ultimate displacement $\left(S_{a}\right)$ are used as the results. It is observed from Table 2 that the variations in $U_{b}$ and $S_{a}$ are $0.86 \%$ and $0.2 \%$, respectively.
3.2. Multiple Inflatable Anchor Test. It was concluded from Zheng et al. [14] that the main influencing factors of group anchors are the spacing $(R)$, number, and arrangement of the anchors. Thus, the multiple inflatable anchor tests are divided into groups based on their layouts, number of anchors, and spacing of the anchors. It should be noted that 


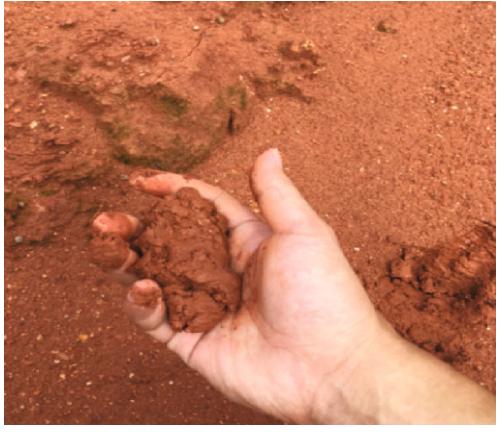

FIGURE 3: Environment of the drilled soil for testing.

the multiple inflatable anchor tests are charged with the same pressure $(0.1 \mathrm{MPa})$. The number of inflatable anchors is two (Figure 6(a)), three (Figure 6(b)), and four (Figure 6(c)), named the two-anchor group $\left(G_{\text {two }}\right)$, three-anchor group $\left(G_{\text {three }}\right)$, and four-anchor group $\left(G_{\text {four }}\right)$, respectively. Since all groups are affected by anchors with different spacing, the best spacing is determined by the test results of all the anchor groups. Meanwhile, the load-displacement curves are obtained, as shown in Figure 7. The layouts of $G_{\text {three }}$ and $G_{\text {four }}$ are triangular and rectangular, respectively, with varied spacing as shown in Figure 6(d).

\section{Experimental Results}

4.1. Two Inflatable Anchor Tests. The two inflatable anchor tests included five groups with spacing of the anchors, and the testing results are presented in Table 3 . It should be mentioned that the diameters of the inflatable anchors in this study are identical, although different diameters may be used in practical engineering. Thus, the radius ratio, the ratio of the spacing of inflatable anchors to the equivalent expanding section diameter of an inflatable anchor, is $5.15 \mathrm{~cm}$, as seen in Table 1. This was introduced by Cao et al. [10]. Under this condition, the variation law of the uplift load-displacement of the inflatable anchor is studied. The total ultimate displacement of anchors is the displacement at the point when the anchors fail. For instance, the displacement of anchors is the value of the horizontal axis at the second to last dots in Figure 7.

The uplift bearing capacity versus displacement responses $(Q-S)$ of the multiple inflatable anchors with varied spacing in clay are shown in Figure 7. For ease of observation, the total ultimate uplift bearing capacity and its corresponding ultimate displacement of the anchors versus the changing $R$ in $G_{\text {two }}$ is depicted in Figure 8. It can be seen from Table 3 and Figures 7 and 8 that with the spacing of $15 \mathrm{~cm}$, the anchor load continues to increase with the displacement until a peak value reached at a critical displacement $(R=35 \mathrm{~cm})$, beyond which the anchor load tends to be nearly constant. Such a phenomenon occurs because the clay has undergone clear failure. Consequently, the anchor could not support a greater load, and the rate of increase in load with displacement attains a steady maximum value. The corresponding deformation is considered to be the ultimate displacement.

Nearly similar behavior was observed in the case of $25 \mathrm{~cm}$, $35 \mathrm{~cm}, 45 \mathrm{~cm}$, and $55 \mathrm{~cm}$ anchor spacing in $G_{\text {three }}$ and $G_{\text {four }}$. It can be clearly seen from Figures 7 and 8 that the maximum uplift bearing capacity occurs when the anchor spacing is $35 \mathrm{~cm}$. Therefore, the optimal anchor spacing $R_{b}$ is $35 \mathrm{~cm}$, and the corresponding optimal radius ratio is 6.84 , according to Table 3 .

To accurately analyze the multiple inflatable anchors, the ECO of the multiple inflatable anchors, $\psi$, which can help to evaluate the effect of the group anchor, can be written as

$$
\psi=\frac{F_{n}}{n Q_{u}},
$$

where $F_{n}$ is the ultimate uplift bearing capacity of the group anchor, $Q_{u}$ is the ultimate bearing capacity of a single inflatable anchor, and $n$ is the number of anchors. It can be obviously find that ECO is an index, whether the ultimate uplift bearing capacity of group anchors is large than the $n$ times of the total the ultimate uplift bearing capacity of $n$ single anchors or not can be reflected. If the ECO is larger than 1, that means the ultimate uplift bearing capacity of group anchors is enlarged. The ECO is affected by the anchor spacing. The coefficient of multiple inflatable anchors for $G_{\text {two }}$ is calculated according to Eq. (1) and listed in Table 4.

The ultimate uplift bearing capacity of anchors initially increases with the spacing but decreases once it reaches a maximum value. Correspondingly, the ECOs of multiple inflatable anchors have similar trends. When the spacing between the two anchors is less than $R_{b}$, the bearing capacity of each anchor is lower than when using a single anchor. When the spacing is $R_{b}$, the coefficient effect of the group anchor is maximized. However, if the spacing is larger than $R_{b}$, the working state of each anchor is close to that of a single anchor.

4.2. Three-Anchor and Four-Anchor Group Testing. The spacing of $G_{\text {three }}$ and $G_{\text {four }}$ is based on the $R_{b}$ value that was determined by $G_{\text {two }}$. The testing results are listed in Table 5 . The uplift bearing capacity versus displacement responses of $G_{\text {three }}$ and $G_{\text {four }}$ with $35 \mathrm{~cm}$ spacing are shown in Figures 7(b) and 7(c). It can be concluded from Figure 7 that the failure behavior of inflatable anchors generally exhibits a trimodal deformation, i.e., the behavior is mostly elastic at the beginning, when the load-deformation response is almost linear. In this stage, the load-deformation response exhibits as linear due to the friction resistance along the rods of the anchors and the enlarged rubber membrane. The mechanical reaction is like a spring that exhibits an elastic deformation. Then, the pores in the clay were squeezed until they gradually closed at the end, as the load increased. The loaddeformation response tends to be nonlinear due to the plastic behavior of soils, and the rupture propagates to an adjacent plastic region in the rubber membrane. Finally, the deformations stabilize because of the failure of the rubber membrane.

\section{Discussions}

On one hand, the average ultimate bearing capacities from three- and four-anchor tests are $453.3 \mathrm{~N}$ and $446.3 \mathrm{~N}$, respectively, while the average ultimate bearing capacity from the two-anchor test is $454 \mathrm{~N}$. That is, when $R_{b}$ is $35 \mathrm{~cm}$, the layout with two anchors is optimal due to its maximum ultimate 


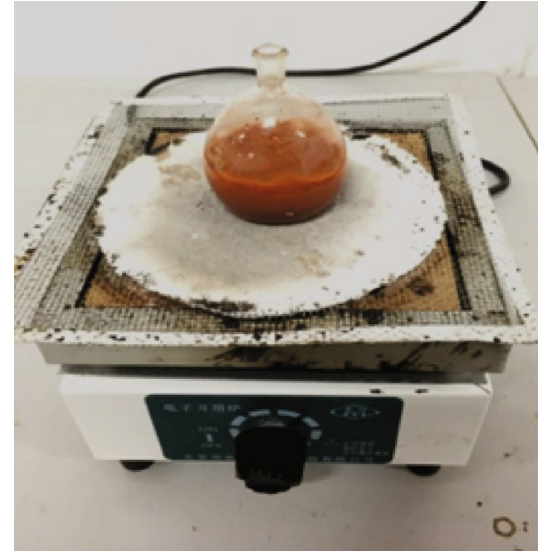

(a) Specific gravity bottle method

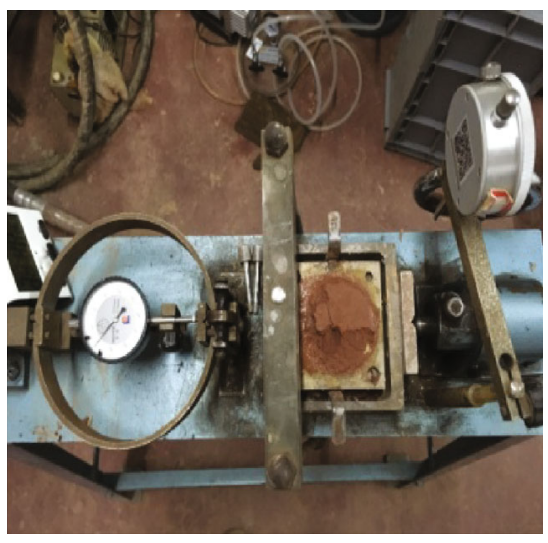

(c) Direct shear test

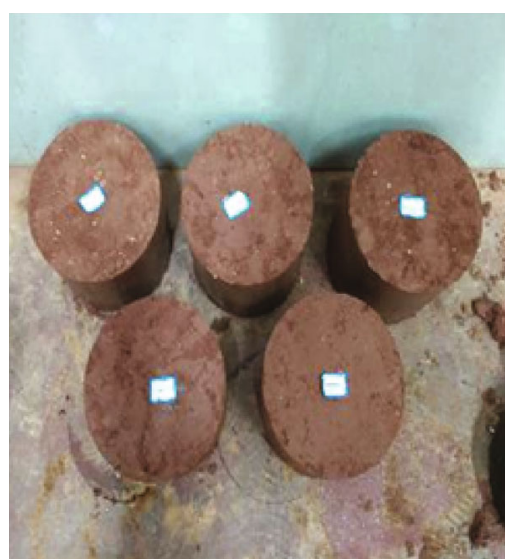

(b) Compaction test

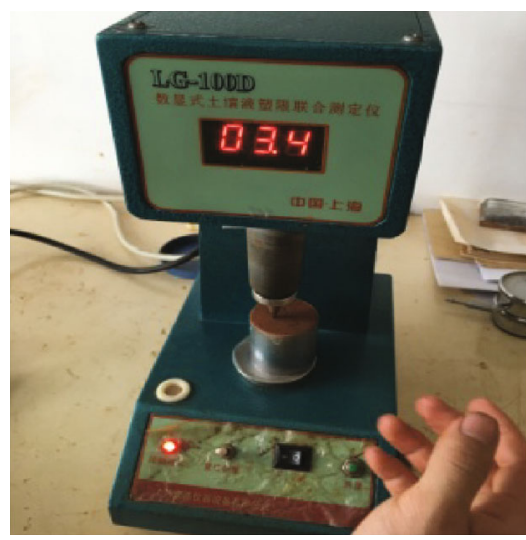

(d) Liquid-plastic combine test

FIGURE 4: Experiments of the testing soil.

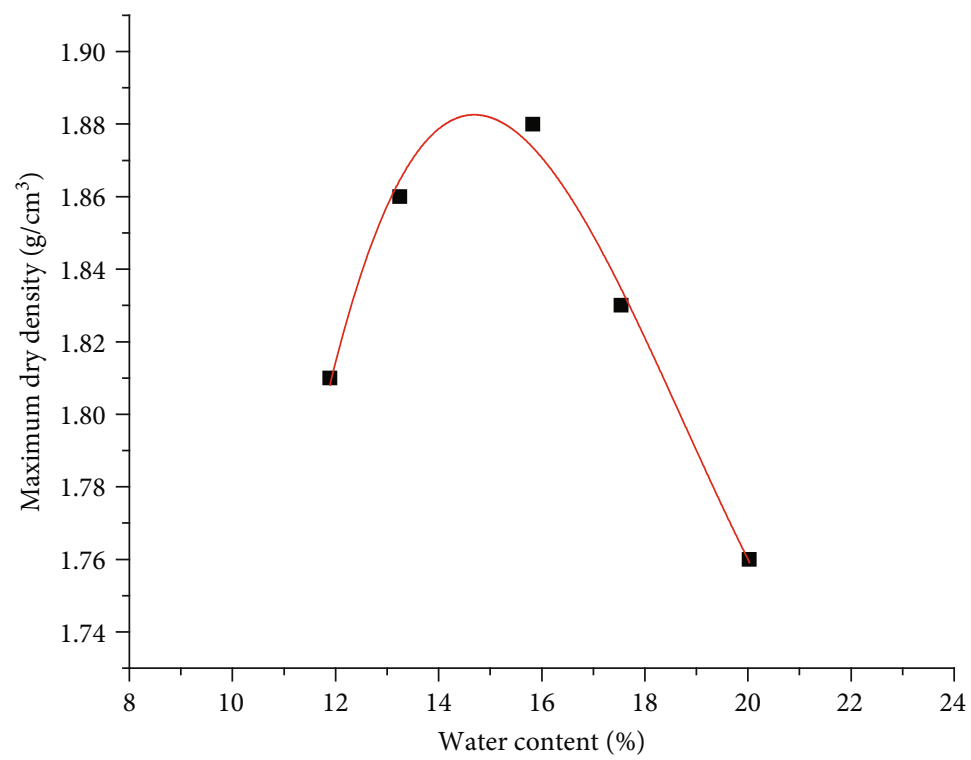

Figure 5: The curve of moisture content versus dry density. 
TABle 2: Testing data from a single inflatable anchor.

\begin{tabular}{|c|c|c|c|c|c|c|c|}
\hline No. & $\begin{array}{l}\text { Embedment } \\
\text { depth }(\mathrm{cm})\end{array}$ & $\begin{array}{c}\text { Charging } \\
\text { pressure }(\mathrm{MPa})\end{array}$ & $\begin{array}{l}\text { Equivalent diameter } \\
\qquad D(\mathrm{~mm})\end{array}$ & $\begin{array}{l}\text { Ultimate bearing } \\
\text { capacity }\left(U_{b} / \mathrm{N}\right)\end{array}$ & $\begin{array}{c}\text { Ultimate } \\
\text { displacement } S(\mathrm{~mm})\end{array}$ & $\begin{array}{c}\text { Average } \\
U_{b}(\mathrm{~N})\end{array}$ & $\begin{array}{l}\text { Average } S \\
(\mathrm{~mm})\end{array}$ \\
\hline $\mathrm{C} 1$ & 45 & 0.1 & 51.19 & 401 & 8.19 & \multirow{2}{*}{404.5} & \multirow{2}{*}{8.21} \\
\hline $\mathrm{C} 2$ & 45 & 0.1 & 51.90 & 408 & 8.23 & & \\
\hline
\end{tabular}

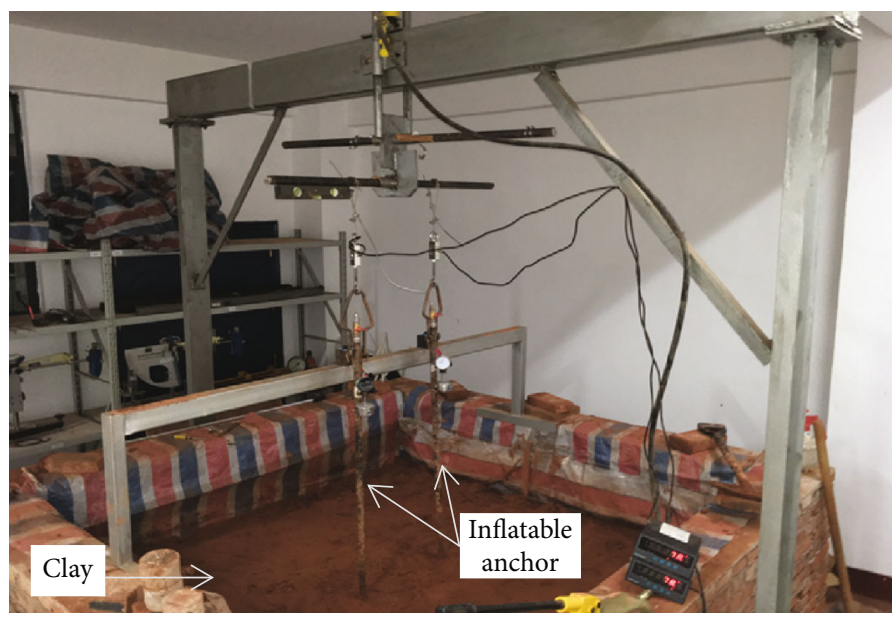

(a) Two-anchor test $\left(G_{\mathrm{two}}\right)$

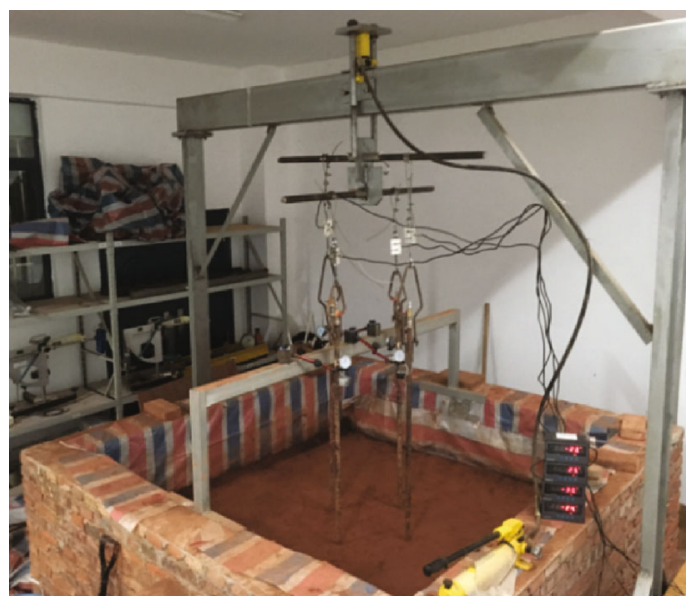

(c) Four-anchor test $\left(G_{\text {four }}\right)$

$\circ$ Anchors

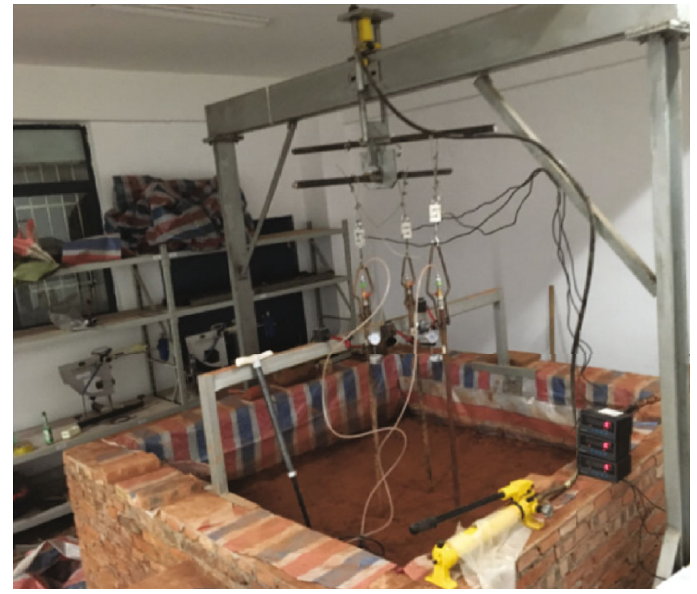

(b) Three-anchor test $\left(G_{\text {three }}\right)$

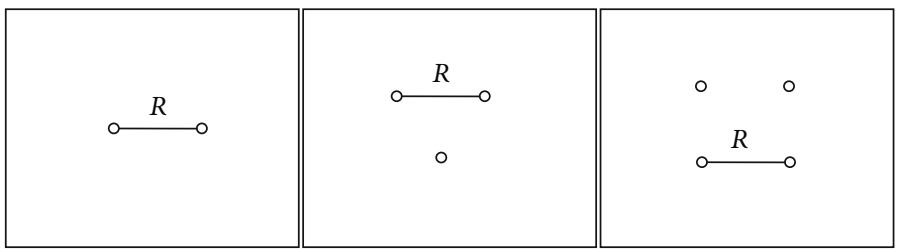

FIgURE 6: Schematic of the plane arrangement of two-, three-, and four-anchor tests.

uplift bearing capacity. On the other hand, the ultimate displacements of the three- and four-anchor tests are $7.76 \mathrm{~cm}$ and $7.39 \mathrm{~cm}$, respectively, while the result of the two-anchor test is $8.25 \mathrm{~cm}$. This is mainly because the failure rate of the rubber membrane in $G_{\text {two }}$ was faster than that in $G_{\text {three }}$ and $G_{\text {four }}$. Clearly, with an increase in the number of anchors, the uplift bearing capacity of multiple inflatable anchors increases substantially. Nevertheless, the displacement response of multiple inflatable anchors decreases as the number of anchors increases. In addition, compared with $G_{\text {four }}$, the layout of $G_{\text {three }}$ is better due to its high $\psi$. Thus, the appropriate layout of multiple inflatable anchors is recommended as shown in Figure 9.

For the mechanism of conventional anchors, it is well known that the bearing capacity of each anchor decreases when group anchors are used in engineering. Specifically, the ECOs of conventional group anchors are less than 1. In contrast, in $G_{\text {two }}, G_{\text {three }}$, and $G_{\text {four }}$, the ECO of the group anchors is greater than 1 when the spacing is a certain value. This is mainly because the forces between (or among) the inflatable anchors were caused by charging the rubber membrane, and the resultant reaction was impacted by the weight of the clay.

In addition, some theoretical calculations should be used to explain this phenomenon with end-enlarged-piles in foundations. The expansion created by charging the rubber membrane can be considered a type of end-enlarged-pile in the foundation because of their similar shapes. The uplift bearing capacity of inflatable anchors is regarded as the uplift bearing capacity of piles. This approach was described by Hanna et al. 


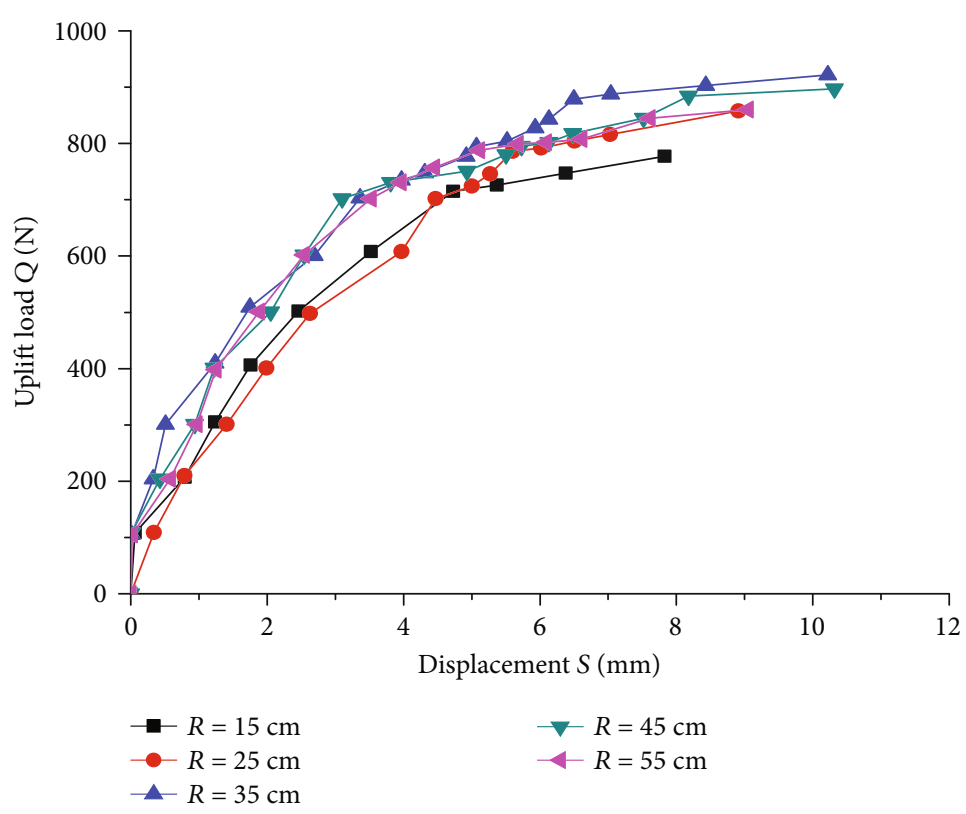

(a) $G_{\text {two }}$

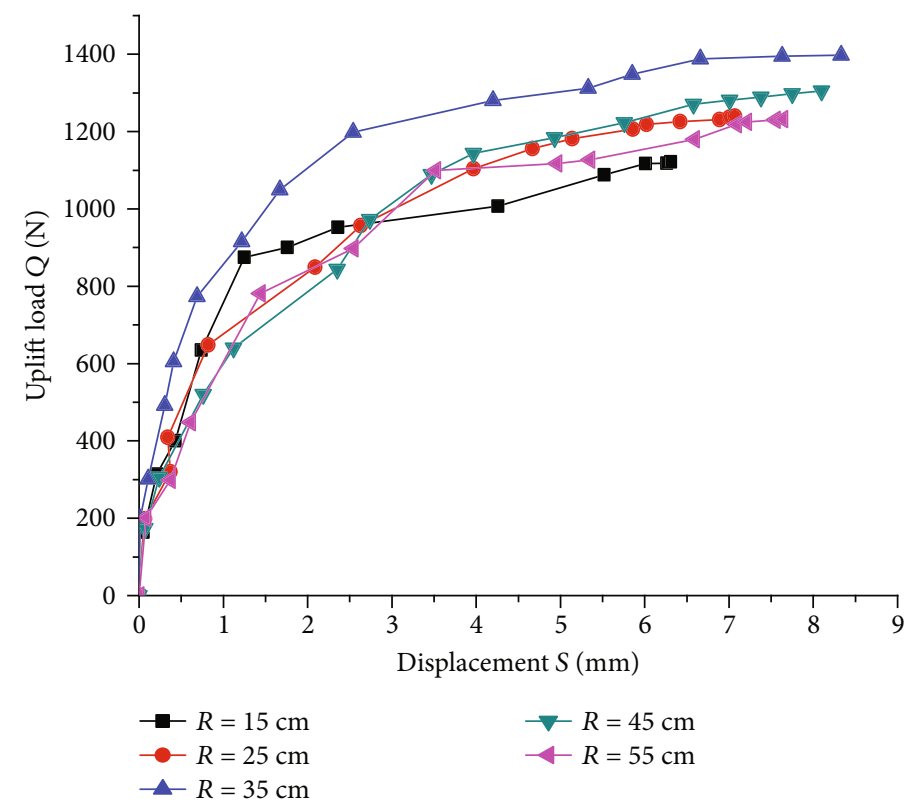

(b) $G_{\text {three }}$

Figure 7: Continued. 


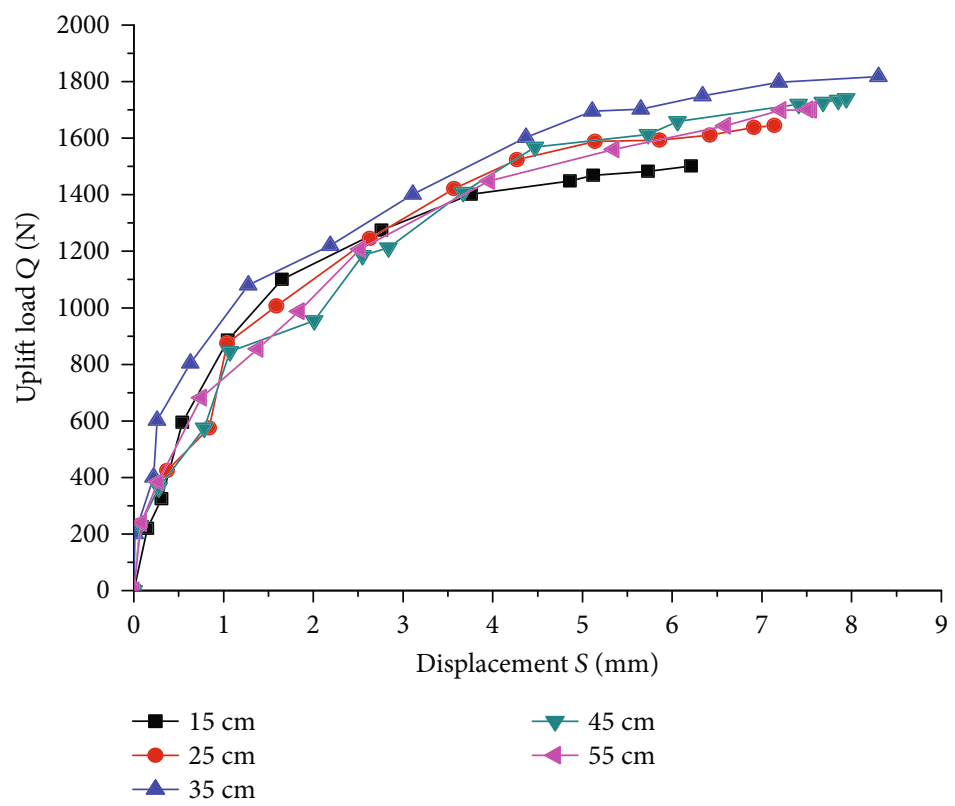

(c) $G_{\text {four }}$

Figure 7: $Q$ - $S$ curves of multiple anchors with different spacing.

TABLE 3: Two-anchor testing results.

\begin{tabular}{|c|c|c|c|c|c|}
\hline Groups & No. & Spacing $R(\mathrm{~cm})$ & Radius ratio & Total ultimate bearing capacity $(\mathrm{N})$ & Total ultimate displacement $(\mathrm{mm})$ \\
\hline \multirow{3}{*}{ G } & G1 & \multirow{3}{*}{15} & \multirow{3}{*}{2.93} & \multirow{3}{*}{747} & \multirow{3}{*}{6.37} \\
\hline & G2 & & & & \\
\hline & G3 & & & & \\
\hline \multirow{2}{*}{$\mathrm{H}$} & $\mathrm{H} 1$ & \multirow{2}{*}{25} & \multirow{2}{*}{4.88} & \multirow{2}{*}{826} & \multirow{2}{*}{7.07} \\
\hline & $\mathrm{H} 2$ & & & & \\
\hline \multirow{2}{*}{$\mathrm{J}$} & $\mathrm{J} 1$ & \multirow{2}{*}{35} & \multirow{2}{*}{6.84} & \multirow{2}{*}{908} & \multirow[b]{2}{*}{8.25} \\
\hline & $\mathrm{J} 2$ & & & & \\
\hline \multirow{2}{*}{ K } & $\mathrm{K} 1$ & \multirow{2}{*}{45} & \multirow{2}{*}{8.79} & \multirow{2}{*}{869} & \multirow{2}{*}{8.09} \\
\hline & $\mathrm{K} 2$ & & & & \\
\hline \multirow{2}{*}{$\mathrm{L}$} & L1 & \multirow{2}{*}{55} & \multirow{2}{*}{10.74} & \multirow{2}{*}{852} & \multirow{2}{*}{7.64} \\
\hline & $\mathrm{L} 2$ & & & & \\
\hline
\end{tabular}

[15], Chattopadhyay and Pise [16], and Murray and Geddes [17]. There are some well-accepted calculation methods, such as the friction cylinder method [18] and MeyerhofAdams method [19]. The general formulas are expressed as

$$
\begin{gathered}
Q_{u}=Q_{s}+Q_{p}, \\
Q_{s}=\pi D L q_{s}, \\
Q_{p}=\frac{\pi\left(D^{2}-d^{2}\right)}{4} \beta_{c} \gamma_{m} H,
\end{gathered}
$$

where $Q_{u}$ is the ultimate antiuplift capacity; $Q_{s}$ is the side resistance of the enlarged end cylinder; $Q_{p}$ is the tip resistance of the enlarged cylinder; $D$ is the diameter of the rubber membrane; $q_{s}$ is the bond strength; $d$ is the anchor diameter; $\gamma_{m}$ and $H$ are the unit weight of soils and embedment depth, respectively; and $\beta_{c}$ is the bearing coefficient of the enlarged head.

The uplift bearing capacity of inflatable anchors is mainly provided by the expansion of the rubber membrane at the bottom, and it is treated as a cone shape in the pile foundation. The new formulas are expressed as follows

$$
\begin{gathered}
Q_{u}^{\prime}=Q_{s}^{\prime}+Q_{p}^{\prime}, \\
Q_{s}^{\prime}=\pi D L q_{s}^{\prime}, \\
Q_{p}=\frac{\pi\left(D^{\prime 2}-d^{2}\right)}{4} \beta_{c} \gamma_{m} H,
\end{gathered}
$$

where $Q_{u}^{\prime}$ is the enlarged ultimate antiuplift capacity; $Q_{s}^{\prime}$ is the enlarged side resistance of the cylinder; $Q_{p}^{\prime}$ is the enlarged tip 


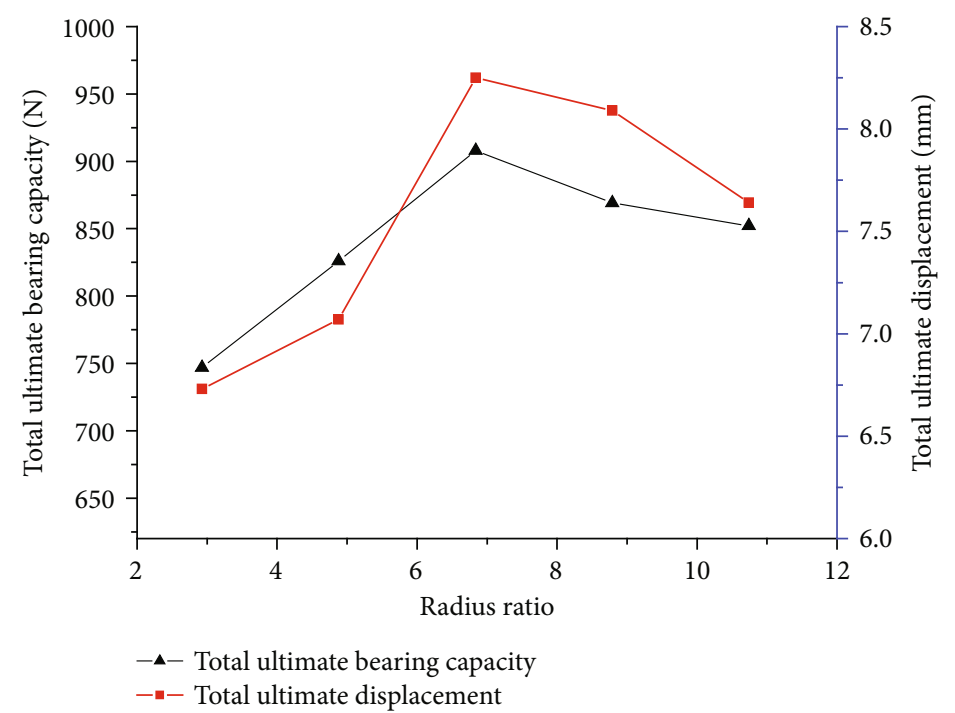

Figure 8: The total ultimate bearing capacity $\left(G_{\mathrm{two}}\right)$ and total limit displacement vs. $R$.

TABle 4: The ECO of multiple inflatable anchors for two anchors with different spacing.

\begin{tabular}{cccr}
\hline Anchor number & Anchor spacing $R(\mathrm{~cm})$ & Ultimate uplift bearing capacity $(\mathrm{N})$ & $\psi$ \\
\hline & 15 & 373.5 & 0.923 \\
& 25 & 413 & 1.021 \\
2 & 35 & 454 & 1.122 \\
& 45 & 434.5 & 1.074 \\
& 55 & 426 & 1.053 \\
\hline
\end{tabular}

TABLE 5: Comparison test results of three and four anchors.

\begin{tabular}{|c|c|c|c|c|c|c|c|}
\hline $\begin{array}{l}\text { Anchor } \\
\text { grouping }\end{array}$ & $\begin{array}{l}\text { Anchor } \\
\text { number }\end{array}$ & $\begin{array}{c}\text { Anchor } \\
\text { spacing }(\mathrm{cm})\end{array}$ & $\begin{array}{c}\text { Radius } \\
\text { ratio }\end{array}$ & $\begin{array}{c}\text { Total ultimate bearing } \\
\text { capacity }(\mathrm{N})\end{array}$ & $\begin{array}{c}\text { Average ultimate bearing } \\
\text { capacity }(\mathrm{N})\end{array}$ & $\begin{array}{c}\text { Total ultimate } \\
\text { displacement }(\mathrm{mm})\end{array}$ & $\psi$ \\
\hline \multirow{3}{*}{ M } & M1 & & & \multirow{3}{*}{1360} & \multirow{3}{*}{453.3} & \multirow{3}{*}{7.76} & \multirow{3}{*}{1.121} \\
\hline & M2 & & & & & & \\
\hline & M3 & & & & & & \\
\hline \multirow{4}{*}{$\mathrm{N}$} & N1 & 35 & 6.84 & \multirow{4}{*}{1785} & \multirow{4}{*}{446.3} & \multirow{4}{*}{7.39} & \multirow{4}{*}{1.103} \\
\hline & $\mathrm{N} 2$ & & & & & & \\
\hline & N3 & & & & & & \\
\hline & N4 & & & & & & \\
\hline
\end{tabular}

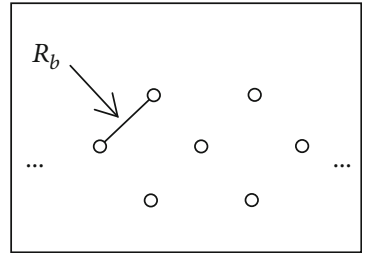

Figure 9: Recommended layouts of multiple inflatable anchors. resistance of the enlarged cylinder; $q_{s}^{\prime}$ is the bond strength after further compaction of the clay; $D^{\prime}$ is the increased diameter of the rubber.

As shown in Figure 10, the rubber membrane will expand after inflated, $D$ is increased substantially, and the nearby clay will be compressed. Subsequently, the bond strength after further compaction of the clay increases, increasing both $Q_{s}^{\prime}$ and $Q_{p}^{\prime}$. The ECO of multiple inflatable anchors is induced and enlarged to some extent by the above-mentioned process. In contrast, $Q_{s}^{\prime}$ decreased due to the decreasing $q_{s}^{\prime}$, and 


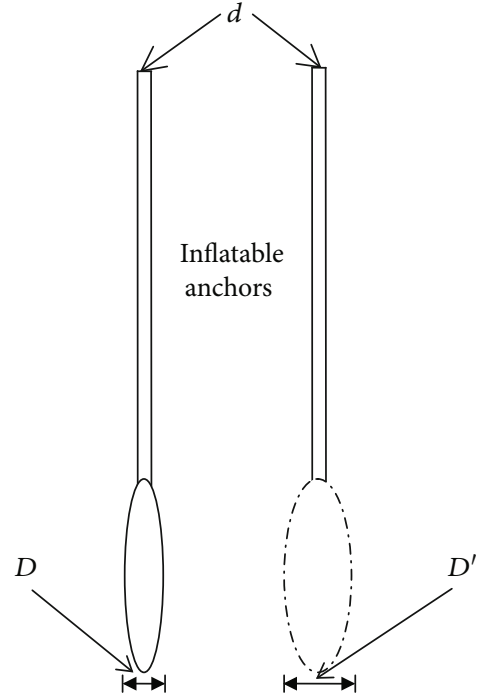

FIGURE 10: Deformation diagram of the rubber after expansion.

$Q_{p}^{\prime}$ did not change; hence, the ECO of conventional group anchors is less than 1 .

\section{Conclusions}

In this paper, an experimental study of the failure mechanism of multiple inflatable anchors in clay was presented. A series of model tests was conducted, and the influencing factors, spacing, number, and layout of the anchors were investigated. The conclusions are summarized as follows:

(1) The failure of inflatable anchors in clay generally occurs in three stages. Firstly, the behavior is mostly elastic when the load-deformation response is almost linear, although a mild rupture forms at the bottom of the anchor. Secondly, the rupture propagates to an adjacent elastic region; therefore, the anchor movement accelerates, and the deformations tend to be nonlinear. Finally, the deformations stabilize due to the failure of the rubber membrane in the anchors.

(2) The optimal anchor spacing $\left(R_{b}\right)$ in clay is $35 \mathrm{~cm}$. When the spacing is less than $R_{b}$, the bearing capacity of each anchor is lower than when using a single anchor. The ECO of multiple inflatable anchors is maximized when the spacing is $R_{b}$. The bearing capacity of each anchor is close to that of a single anchor if the spacing is larger than $R_{b}$

(3) The ECO of multiple inflatable anchors is greater than 1 , which is different from that of conventional anchors. Such a phenomenon occurs mainly because of the enlarged side resistance $Q_{s^{\prime}}^{\prime}$, due to the charged rubber membrane and the enlarged tip resistance $Q_{p}^{\prime}$

(4) The recommended layout of multiple inflatable anchors in clay is in the shape of a cinquefoil

It should be noted that the above conclusions are appropriate in clay when the specific gravity is 2.692 , the cohesion is $17.6 \mathrm{kPa}$, and the friction angle is $23.1^{\circ}$. If the soft soil is changed, the results may be different.

\section{Data Availability}

Data are available on request.

\section{Conflicts of Interest}

The authors declare that they have no conflicts of interest.

\section{Acknowledgments}

The work is supported by the National Natural Science Foundation of China (Nos. 52078211 and 51909087), the Natural Science Foundation of Hunan Province, China (Grant No. 2020JJ4021), Research Fund of Hunan University of Science(No. E51975), Open Fund of National Engineering Laboratory of Highway Maintenance Technology (Changsha University of Science \& Technology, kfj190107), and Scientific Research Projects of Hunan Education Department (18K064).

\section{References}

[1] A. Balla, "The resistance to breaking out of mushroom foundations for pylons," in Proceeding of 5th International Conference of Soil Mechanics and Foundation Engineering, pp. 569-576, Paris, France, 1961.

[2] J. L. Borges and M. S. Gonçalves, "Jet-grout column-reinforced soft soils incorporating multilayer geosynthetic-reinforced platforms," Soils and Foundations, vol. 56, no. 1, pp. 57-72, 2016.

[3] E. A. Dickin, "Uplift behavior of horizontal anchor plates in sand," Journal of Geotechnical Engineering, vol. 114, no. 11, pp. 1300-1317, 1988.

[4] H. L. Liu, C. W. W. Ng, and K. Fei, "Performance of a geogrid reinforced and pile-supported highway embankment over soft clay: case study," Journal of Geotechnical and Geoenvironmental Engineering, vol. 133, no. 12, pp. 1483-1493, 2007.

[5] T. A. Newson, F. W. Smith, and P. Brunning, "An experimental study of inflatable offshore anchors in soft clays," Proceedings of ICOF 2003, 2003, Dundee, Britain, 2003, 2003.

[6] W. X. Peng, Y. Wang, and J. W. Cao, "Formation and analysis of the numerical simulation element for the inflatable anchor," Engineering Investigation, vol. 38, no. 6, pp. 6-9, 2010.

[7] W. Peng, S. Xu, J. Cao, and Q. Yin, "Nonlinear Finite element analysis of Mechanical properties of inflatable anchors," Chinese Journal of Rock Mechanics and Engineering, vol. 31, Supplement 1, pp. 3104-3109, 2012.

[8] J. J. Mo, Experimental Study on Mechanical Characteristics of Inflatable Anchor with Several Airbags, [Ph.D. thesis], Central South University, Changsha, 2014.

[9] J. W. Cao and Z. B. Peng, "Experimental study on mechanical characteristics of inflatable anchors in soft clay," Chinese Journal of Geotechnical Engineering, vol. 33, no. 9, pp. 1399-1404, 2011.

[10] J. W. Cao, Z. B. Peng, W. X. Peng, Z. M. He, and Q. Yin, "Model test study of inflated anchors in sands," Rock and Soil Mechanics, vol. 32, no. 7, pp. 1957-1962, 2011. 
[11] M. H. Yang, H. Zou, M. H. Zhao, and H. Luo, "Bearing performance of new uplift anchor with side branches," Journal of Central South University(Science and Technology), vol. 46, no. 12, pp. 4634-4639, 2015.

[12] T. Xiao and Y. He, "Experimental study of an inflatable recyclable anchor," Advances in Materials Science and Engineering, vol. 2018, Article ID 6940531, 10 pages, 2018.

[13] X. X. Yang, Y. F. Jiao, and Y. Y. Yang, "The development and test of aerated expansion controlled anchors," Rock and Soil Mechanics, vol. 2020, no. 3, pp. 1-9, 2019.

[14] X. Y. Zheng, Y. Y. Xia, L. L. Zhang, and X. Liu, "Research of reinforcement mechanism of multi anchorage effect by prestressed anchor cable," Journal of Wuhan University of Technology, vol. 32, no. 11, pp. 62-67, 2010.

[15] T. H. Hanna, R. Sparks, M. Yilmaz, and G. G. Meyerhof, "Anchor behavior in sand (discussion)," Journal of Soil Mechanics and Foundation Division, vol. 99, no. sm5, p. 414, 1973.

[16] B. C. Chattopadhyay and P. J. Pise, "Breakout resistance of horizontal anchors in sand," International Journal of Rock Mechanics and Mining Sciences \& Geomechanics Abstracts, vol. 24, no. 4, p. 152, 1987.

[17] E. J. Murray and J. D. Geddes, "Uplift of anchor plates in sand," Journal of Geotechnical Engineering, vol. 113, no. 3, pp. 202-215, 1987.

[18] E. A. Dickin and F. Leung, "Evaluation of design methods for vertical anchor plates," Journal of Geotechnical Engineering, vol. 111, no. 4, pp. 500-520, 1985.

[19] G. G. Meyerhof and J. I. Adams, "The ultimate uplift capacity of foundations," Canadian Geotechnical Journal, vol. 5, no. 4, pp. 225-244, 1968. 